\title{
Paths to Knowledge Management in Small and Medium-Sized Hotels
}

\author{
Mik Kim \\ RMIT University, Australia \\ Wusheng Zhang \\ Victoria University, Australia
}

\begin{abstract}
The purpose of this paper is to investigate what path options can facilitate small and medium-sized hotels' knowledge management? And how the options are realised by them? In order to answer these questions, this study undertook an empirical investigation into the current status and practice of knowledge management in small and medium-sized hotels. The empirical investigation was performed through thirteen face-to-face in-depth interviews with owners and managers in small and medium-sized hotels. While the interview method is selected so as to answer the questions, secondary data are utilised to support this study such as in defining the research questions and informing the study findings. This study observed that there were four broad approaches to the way in which hotels put their paths to knowledge management. Each type of the paths is named as: Match, Combination, Divergence, and Specialisation. As arguably, knowledge management is both part of the cost of doing business and the most likely source of competitive advantage, it is as important to the sole operator as to the large corporation. By understanding the different options, hotels will be able to make better decisions in the choice of their suitable paths to knowledge management.
\end{abstract}

\section{Keywords}

Knowledge management, Small and medium-sized hotels Prologue

\section{Introduction}

Managing individual and organisational knowledge has now become an imperative to create sustainable competitive advantage especially, in large corporations. However, to date there has been relatively little research conducted into what strategic path options can facilitate small and medium-sized hotels' knowledge management? And how the options are realised by them? In order to answer these questions, an empirical investigation was undertaken through thirteen face-to-face in-depth interviews with owner/managers in the hotels. The investigation was focussed on the practices and issues in such hotels' knowledge management. While the interview method is selected so as to answer the questions, secondary data through reviewing extant literatures are utilised to support this study such as in defining

Copyright (C) 2008 Victoria University. This document has been published as part of the Journal of Business Systems, Governance and Ethics in both online and print formats. Educational and non-profit institutions are granted a nonexclusive licence to utilise this document in whole or in part for personal or classroom use without fee, provided that correct attribution and citation are made and this copyright statement is reproduced. Any other usage is prohibited without the express permission of the the research questions and informing the empirical study findings.

\section{Theoretical Background}

As suggested by Drucker in 1993, knowledge is now the new basis of competition in post-capitalist society and only knowledge resources have unlimited potential for growth (Davenport and Prusak 
1998; Nonaka and Takeuchi 1995). A view of knowledge as a key firm resource focuses on the internal side of the firm's resources and capabilities. One of the basic propositions of the resource-based view of the firm is that firms differ as to their resource endowments (Barney, 1991; Prahalad and Hamel 1990; Wernerfelt, 1984). The resource-based view argues that inter-firm performance differences occur through heterogonous access to valuable resources. This creates isolating mechanisms representing entry barriers at the industry level and mobility barriers at the industry group level, that sustain the firm's competitive advantage (Rumelt 1984; Mahoney and Pandian 1992). In the resource-based view, knowledge resources are highly valuable, unique to the organisation, difficult to copy and substitute (Barney 1991; Boisot 1998; Grant 1991) and can lead to competitive advantage.

Competitive advantage based on resources and capabilities is potentially more sustainable than the traditional market-based approach (Porter 1980, 1985). In 1980, Michael Porter published his influential work Competitive Strategy: Techniques for analysing industries and competitors. Porter's model of five competitive forces allowed managers to assess the attractiveness of the market and establish the most competitive position within that market. Porter's (1985) concept of the 'value chain' was a further advance in that allowing managers to determine potential sources of competitive advantage by examining the activities that their organisation undertook, and the links between them. The market-based approach concerns the organisation's environment focusing on selecting an attractive industry and positioning an organisation attractively within this industry through one of the two generic strategies cost-leadership or differentiation. However, the market-based approach was criticised in its extreme form, based solely on market positioning and the consideration of organisational resources mostly only in the implementation phase.

Building on the resource-based view of the firm, the knowledge-based view of the firm contends that knowledge is the key resource and the only resource capable of creating sustainable competitive advantage. In the knowledge-based view of the firm, internal resources and capabilities such as knowhow, customer knowledge, efficient processes, and expertise embedded in routines and practices that the firm transforms into valuable products and services are the keys to achieving sustainable competitive advantage (Grant 1996; Davenport and Prusak 1997; Boisot 1998; Teece 1998). The two views are interrelated in that knowledge has emerged as the most important organisational resource (Nonaka 1994; Grant 1996; Spender 1996). Both the resource-based view and the knowledge-based view of the firm have advanced the discussion on competitive advantage by acknowledging the proactive nature of firm strategies.

There is a growing number of frameworks and models in literature as organisational learning (Senge 1990), networking (Everett 1995; Powell 1990), process/cycle (AP\&QC 1996; Buowitz and Williams 2000; Meyer and Zack 1996; Ruggles 1998; Wiig 1993), intellectual capital (Bohn 1994; Eccles 1991; Edvinsson and Malone 1997; Kaplan and Norton 1996; Roos and Roos 1997; Stewart 1997), social construction (Argyris and Schön 1996; Demarest 1997), communities of practice (Brown and Duguid 1998; Wenger 1998), codification v personalisation (Hansen et al. 1999), social interaction (Sveiby 1997), a set of structures (Earl 2001), tacit versus explicit knowing (Nonaka and Takeuchi 1995; Polanyi 1966) and societal knowledge management (Wiig 2007). Those models, frameworks, and a set of methods focus on the conceptual level of knowledge management, more suitable for large organisations that are in a better position than smaller ones in many aspects.

Knowledge management studies in small and medium-sized hotels setting are scarce in the literature which necessitates drawing research from other small and medium-sized enterprises. For example, the comparison study done by McAdam and Reid (2001) illustrate the perception of knowledge management in both large organisations and small and medium-sized enterprises. In exploring knowledge management in small and medium-sized enterprises, Sparrow (2001) emphasises the need to recognise the different mental models of individuals and to share their personal understanding in the development of knowledge management processes. With the study of twelve innovative Dutch small and medium-sized enterprises from the industrial and business service sectors, uit Beijerse (2000) examines the extent to which knowledge management is being practised. 
By investigating some of the unique knowledge management issues facing smaller firms in German industry, Wickert and Herschel (2001) discuss techniques that could be employed to acquire and retain knowledge. Another study in small and medium-sized enterprises' knowledge management is discussed by Matlay (2001). The study focuses on competitive advantage in organisational learning in the UK small businesses. In 2004 Wong and Aspinwall characterise knowledge management in the small business environment based on literature review. A recent study by Desouza and Awazu (2006) reports their findings of five peculiarities at twenty-five small and medium-sized enterprises. Most of knowledge management studies in small and medium-sized enterprises have centred on the examination of small and medium-sized enterprises' perceptions towards knowledge management and their practices and developments in the area.

\section{Methodology}

As presented in the theoretical background, there has been limited research into the circumstances of small and medium-sized hotels. In particular, little is known about what path options to knowledge management in small and medium-sized hotels? And how the options are realised by them? In order to answer these questions, the study undertook an empirical investigation into the current status and practice of knowledge management in small and medium-sized hotels. The empirical investigation was performed through thirteen face-to-face in-depth interviews with owner/managers in small and mediumsized hotels. While the interview method is selected so as to answer the questions, secondary data are utilised to support this study such as in defining the research questions and informing the study findings. The secondary data are selected and studied by reviewing extant literatures. Literature review is conducted in Knowledge Management with relevant areas as well as Tourism and Hospitality Management.

This research has used loosely defined semi-structured interview questions that support the interpretive qualitative approach in seeking to understand the perceptions and meanings ascribed by the interviewees. In understanding the data, this study has adopted a set of qualitative analysis methods. The unit of analysis for this research is the small and medium sized hotel sector in Australia, with thirteen face-to-face in-depth interviews being conducted. To maintain confidentiality, each organisation was given a code in which two capital alphabetic letters and one numeric number were combined, such as $\mathrm{CH} 3, \mathrm{HH} 8$, and IH9. The first capital letter and the number are in the same ascending order, in numeric and alphabetic order respectively. For example, the number 3 goes with the letter $\mathrm{C}$, which is the third letter in alphabetical order. Likewise, the number 8 goes with the letter $\mathrm{H}$, which is the eighth letter in alphabetical order. The second capital letter $\mathrm{H}$ is a constant to each hotel signifying Hotel.

\section{An Emerging Concept of Path Knowledge}

While the initial aim of conducting face-to-face in-depth interviews with small and medium-sized hotel owners/managers was focused on the status of knowledge management practices and the issues surrounding these, the compelling concept of path knowledge emerged as interviews progressed. All owners/managers interviewed agreed that growth was the key to strategic success and the foundation for the future of their hotels. Embodying the idea of growth in the corporate vision of small hotels predicated the generation of revenues through offering and delivering physical products and services, knowledge-embedded products and services, or knowledge itself as a product and service. Offering and delivering such products and services is closely related to a variety of knowledge management activities intended to leverage the resources and capabilities of hotels.

A hotel's choice of a path to knowledge management was essentially dependent on two aspects, the sources of revenue generation and knowledge management activities. The two aspects cover the emerging concept of the path knowledge which was uncovered during the data analysis. The path knowledge concept represents hotels' corporate visions in which knowledge management is a part of the integrated business direction and practised differently. The sources of generating revenue refers to the decision on whether the hotel will offer a collection of physical products/services (e.g., bed, food, and 
drink), knowledge embedded products/services (e.g., personalised products/services), or knowledge itself (e.g., hotel franchise knowledge). In the choice of products/services the hotels were involved in different intensity of knowledge management activities to manipulate their resources and capability.

Aside from the two defining aspects, the hotel's internal resources and capabilities in combination with external resources also affect its path to knowledge management. This study observed that there were four broad approaches to the way in which hotels put their paths to knowledge management. The path knowledge concept consists of four distinct types of path options. Each type of the path was named as: Path 1 - Match, Path 2 - Combination, Path 3 - Divergence, and Path 4 - Specialisation. Each path features different extents of the two aspects: 1) the sources of revenue generation; and 2) knowledge management activities. To make this path knowledge concept clear, as follows is the more detailed discussion on each path including the relationship between the paths and determining factors that affect the paths.

\section{Path 1: Match}

In this path, hotels pursue their growth vision by generating revenue through the provision of physical products and services in which the extent of knowledge involvement is extremely limited. The provision of physical products and services refers to the delivery of traditional hotel services such as bed, food and beverage, and other ancillary services to customers. The hotels following this path are owned and operated independently by owner/manager(s) with at least one or two family member(s) such as hotel $\mathrm{BH} 2, \mathrm{CH} 3, \mathrm{FH} 6, \mathrm{GH} 7, \mathrm{HH} 8$, and IH9. These hotels have followed the match path very successfully, finding countless ways to give effect to it. This match path aims to make a suitable match with the offerings of competitors, so that the hotels taking this option can use the match in order to satisfy their customers.

In order to pursue this path, the ability to assess and compare competitors' products and services is important. The management of a hotel focuses on the way in which its offerings are constantly being compared with those of competitors. However, in doing so, the hotels must primarily monitor their own operating costs. The owner/manager at hotel $\mathrm{BH} 2$, physically visits competitor's premises in order to monitor their offerings, looks for differences from his own hotel and then tries to match the offering. This kind of activity can contribute to customer satisfaction and to the continuance of the business. The activities of monitoring and comparing competitors' offerings are also reflected in their marketing efforts. All owners/managers following this path have sought to advertise depended on advertising their hotels through local newspapers, Yellow Pages, flyers, and word-of-mouth referrals. But developing a successfully proven business marketing concept and promoting it through mass media advertising are often beyond the resources of such independent small hotels.

The magnitude of advantage accruing from the match path is likely to be small. Hotels with this path are not likely to be able to match all the changes instituted by competitors such as offering new products and services, reducing the cost of services, renovating the amenities, and/or having more staff. Aside from the capacity to match, it is questionable this approach would lead to a substantial enhancement of market share. The delivery of physical products and services on their own is unlikely to lead to a significant increase in market share or revenue generation. Moreover, there has been little knowledge management activity among hotels following this path, as the concept itself is new to them. They do acquire knowledge routinely from external sources including customers, suppliers, and government agencies, and internally from owners/managers.

The knowledge acquired has been utilised less to explore new areas, than to address current capabilities. In particular, the accumulation and use of knowledge is largely dependent on the subjective perceptions and personal knowledge of owners/managers. For example, in order to match competitors, an owner/manager might opt to be flexible in managing cost structure and customer relations. At hotel $\mathrm{CH} 3$, the owner/manager says that he always listens to his customers and detects the needs and wants of their customers. Afterwards, he tries to make prompt changes to increase customer satisfaction. The changes include offering complimentary drink, and lowering prices of the products and services. 
Flexibility in meeting customer satisfaction and choices as well as in service delivery procedures are key elements in this process. This has helped the business to retain its loyal customers.

As no particular modern information technology has been utilised for knowledge management in the hotels following the match path, the traditional technologies (i.e., telephone, fax and copy machine) are still playing an important role in knowledge sharing and dissemination. The owners/managers in this path do not feel a need for other modern technologies, because the hotels are very small in size and managing knowledge and technology is deemed to be difficult. It is true that it is difficult to manage knowledge even with the help of information technology, since there is a set of complex issues that are interrelated and can not be segmented easily. More specifically, knowledge management activities involve interactions within the configuration of organisational factors such as knowledge, people, technology, strategy and organisational milieu. The application of information technology, no matter how pervasive and sophisticated, does not in itself constitute knowledge management. It is basically a very useful tool that helps people to manage knowledge. It is a support and an enabler.

\section{Path 2: Combination}

The hotels in pursuit of the combination path strive to combine the match path with the management of knowledge to obtain an additional level of differentiation. In the combination path knowledge is more embedded in hotels' products and services than it is in the match path. While the concept of knowledge management is not always well understood by owners/managers, hotels following this path are already aware of the importance of knowledge management in their business practice. Examples of the presence of the combination path can be found at hotels DH4, EH5 and JH10.

In managing their knowledge, they are engaged in such knowledge management activities as acquiring, disseminating, utilising and creating knowledge, by identifying customers' needs, analysing better products and services, having regular communication with internal and external stakeholders, and mentoring and training staff. In these hotels, the knowledge acquired is utilised to create either the service processes or the products and services themselves. The creation of processes and indeed, the reduction of process cycles, involve both the owners/managers and cooperation with business partners in order to make it workable.

In terms of offering products and services, the aim is to deliver more personalised products and services to their customers at very competitive prices. By tailoring these to the specific needs and wants of customers as well as by delivering value for money, they are attracting and retaining more repeat customers. For example, at hotel JH10, a service which offers bed and brunch is a good example of personalisation, in that it meets customer demands for flexibility in meal and sleep times. The key capability necessary for this path is that the hotels are in a position to adapt relatively quickly to the increasingly changing requirements of individual customers. The acquired knowledge in building capabilities as well as in exploring new areas has helped them to enhance market performance.

As a point of comparison, the hotels following the combination path have more opportunities to differentiate their products and services or to reduce the cost of servicing than those pursuing the match path. This is reflected in the fact that the combination path hotels tend to hire more staff than those following the match path. This approach gives the combination hotels better leverage over their competitors, and a greater likelihood of enhancing their market performance. By offering both physical products and services (like the match path) and additionally the knowledge-embedded in these, the combination hotels can increase revenue generation as well as market share. Both the match path hotels and the combination path hotels are market oriented, focussing on customers and competitors. However, the difference between these two groups of hotels and the paths they follow is evident at the level of analysis of competitor activity and change.

The aim in hotels following the combination path is not only to match such changes, but also to provide enhanced knowledge-embedded products and services so as to maintain better customer satisfaction and loyalty. In order to detect changes in competitive position in the market, the hotels closely monitor their 
competitors by watching their own costs and matching the marketing initiatives of their competitors. This approach is particularly common among the hotels in the match path and combination path, but a difference is that the hotels in the combination path looked for an edge in technology as well.

In the combination path, modern technology is one of the most sought after factors. In conjunction with the traditional technology, most of the combination hotels have been utilising the Internet and email systems or their own websites. Like with the hotels in the match path, there is however, no use of any kind of online direct booking facilities such as reservation systems, nor of online payment facilities. According to the owners/managers, the use of the more modern technologies did not contribute to an increase in sales, but did help increase the recognition of their business and customer support service to wider communities. This indicates that the value of these technologies lies in their ability to disseminate information and to help build relationships with external entities such as customers and business partners. This also indicates that there is a need for using technologies in day-to-day operations by providing booking and/or payment facilities which are basic as well as crucial in running business.

\section{Path 3: Divergence}

In this type, revenue is generated through the provision of two kinds of knowledge. One kind of knowledge is the knowledge-embedded in products and services derived from the local application of knowledge generated by the business itself through the hotel's internal development or creation. The other knowledge is supplied by an external organisation (i.e., chain head office), the originator of the knowledge. The knowledge created has been used either in the formation processes of services or in knowledge service itself. Physical products and services for this type of hotels are still important as part of the means of generating new knowledge, and the externally obtained knowledge from the chain head office is becoming commoditised as a part of revenue generator. For example, hotels LH12 and MH13 are independently owned and operated and have a hotel chain affiliation. While these hotels have performed their own knowledge management activities, they must also take into account that external knowledge generated by the chain head office includes knowledge embedded in processes/procedures, manuals, policies, products and services, and business partners. The use of this established external knowledge is clearly beneficial to the hotels.

By using such knowledge, the hotels in the divergence path are able to deliver standardised quality, which could be the source of competitive advantage. Another potential advantage is of the possibility of market control. For instance, the hotel chains can overcome traditional market barriers through some form of partnership. This can involve two levels of partnership, namely vertical and horizontal partnerships. The vertical level entails collaboration with other service/product providers in the tourism industry including destination production and marketing, which enables the hotels to better position themselves in the market. At the horizontal level, collaboration can help to improve service offering and delivery and lower costs. In addition, interaction with fellow franchisees under the same chain agreement is enabling the exchange of ideas and the improvement of operational systems.

As a member of a chain, a hotel franchise has entered into financial and contracted preferred agreements with other business partners. Preferred agreements mean that the hotels within the chain will need to relate predominantly to chain related programs, as the chain head office has preferred relationships with certain organisations. These preferred arrangements are also coupled with room allotment availability, direct buying power and negotiation power with business partners. In the case of partnerships with wholesalers and intermediaries, the dual role of any intermediaries is important in maintaining both potential and existing customers of the hotels. Intermediary travel agents are more inclined to sell products and services that have been packaged in a wholesale program. Although as dual agents they might buy from non-preferred wholesalers in seeking out products and services and pricing that best suit the expressed needs of specific customers.

In forming the partnership, the chain affiliation offers market control, something that is normally beyond the capabilities of small independent hotels. In seeking to control the market, the hotel chains must partner with technology intermediaries. The presence of technology such as the Internet and 
computerised reservation systems is a prerequisite to partner hotels reaching parts of the market that they would be unable to access on their own. At the same time, the Internet has had the effect of taking business away directly from the traditional distribution channels and done so in a highly cost effective manner. Nonetheless, the use of technology and collaboration with business partners and the ability to benefit from them, continue to be challenging areas for the hotels.

While all the hotels in this divergence path have acquired and used external chain knowledge to provide knowledge-embedded products and services, some in addition to this have turned their knowledge into a commercial asset. In other words, with the progress of the franchising business knowledge, some hotels as a franchisor actually operate a hotel business, while at the same time selling the franchise to others. This is one of starting points of specialisation, another type of a path discussed in the next section. The divergence path can bee seen as occupying a middle ground between the combination and the specialisation paths, as the hotels involved not only depend on the characteristics of the match path and the combination path, but have also developed the business to the level of chain affiliation that contributes to market enhancement.

\section{Path 4: Specialisation}

There is an increasing propensity for hotels to use their specialised knowledge as a means of generating revenue. Specialised knowledge here refers to the licensing of franchise businesses by hotel chains. It also includes intellectual property that can be legally protected, for example by a patent, trademark, or copyright. In hotels, the specialised knowledge is traded to clients (i.e., franchisees) who wish to apply it based on contractual agreement. Clients are normally independently owned and operated hotels. Typically, hotels pursuing this type of specialisation path move away from the focus on physical products and services, found in the cases of the match path and the combination path, where the competition is on price or where success depends on volume. Instead of relying on physical products and services to generate revenue, the specialisation path focuses on specialised licensing knowledge, with the aim of operating chain business for which it would serve as head office (i.e., franchisor). Along with the licensing of franchise business, the main roles of a chain head office are to source knowledge products and services to clients, and to provide solutions to their needs, adding value derived from the quality of advice and specialised knowledge.

In this specialisation path, products and services are highly customised, and have a strong focus on the specific needs of clients. Moreover, its inherent value turns specialised knowledge into a commodity that can be sold for profit. Although physical products and services still exist, they are components of bigger systems like processes/procedures, manuals, policies and business partners designed to support franchisees. As revenue generation in the specialisation path comes from the sale of specialised knowledge, the marketing function becomes extremely important to maximising the sales of franchises.

In contrast to the position in the other three paths, managing knowledge in this specialisation path is an essential not only for growth, but also for survival. For example, hotel AH1 is running a chain business whose knowledge management portfolio includes their brand image, the quality delivery of knowledge products and services, and relationships with clients and business partners. In order for the hotel to survive in this knowledge-based business, partnership building is essential and is an area which requires innovation, knowledge and patience due to the involvement of many external entities. The manager at hotel $\mathrm{AH} 1$ acknowledges that the value of establishing partnerships could take the form of the reduction of upfront fees, cost effective advertising and promotional activities, stronger purchasing and volume discounts. Hotel AH1's knowledge in such as documents, computerised databases, reservation systems, processes, and products and services, as well as that residing in employees and management, has been used to serve its both clients and employees.

For delivering the knowledge to clients, hotel KH11 as a franchisor provides regular support to them in accordance with a licensing agreement. Such support includes an induction when a new franchise begins, and assistance with marketing, computerised systems and technical planning. It also includes extensive manuals covering business planning, financial control, operations, customer service, staff 
recruitment and training, advertising, promotion and market research. This regular support is ongoing and given through field support programs and business success programs. Lessons learned and best practices are also provided to franchisees in order to offer improved innovative service operations, products and services extensions, or entire new products and services.

It is a matter of concern that both hotels $\mathrm{KH} 11$ and $\mathrm{AH} 1$ do not have an explicit knowledge management strategy, although are committed to regular strategy reviews and the development of strategic plans. As they have engaged in knowledge management planning as required, there is clearly a need for less adhoc, planned knowledge management, something that is not immutable but flexible and dynamic in the face of change. From their perspectives, marketing the business through high brand recognition and a reputation for consistent quality is the key to the success of their business. Akin to other hotels pursuing different approaches, the goal of the specialisation path is also that of business growth through revenue generation, where managing knowledge is an essential factor rather than an optional extra.

\section{Conclusions}

The path options are practical in nature and effective in small and medium-sized hotels as they take into consideration owners/managers' views. Such paths represent the views of experienced mangers dealt with their business intelligence that arise during the course of business operation. Thus, understanding differences among such approaches in the circumstance of each hotel can help construct better intelligent tourism enterprises as a whole. While a path to knowledge management taken by each hotel owner/manager is not alike, the choice of a path is essentially dependent on the hotel's resources and capabilities. More specifically, the sources of revenue generation, knowledge management activities and technology adoption play key roles in choosing a path to knowledge management. All the hotels interviewed are already in knowledge business although they take different paths. Some hotels focus on offering physical products/services and/or knowledge embedded products/services, others move towards knowledge itself as products/services. In order for this to happen, the hotels apply their internal knowledge as well as externally available knowledge in the course of action. Both divergence approach and specialisation approach are associated with a chain affiliation which provides small hotels with a greater opportunity in revenue generation through controlling the market share or enhancement.

On the contrary, the hotels following the match approach or the combination approach might have only a limited number of ways to differentiate their products/services, either on cost or features. Yet they can still reap rewards and gain a significant edge on competitors when they are able to do so. Regardless of the approaches taken by the hotels, revenue generation was obviously one of the most important elements in achieving their growth vision. The bottom line was for revenue generation in continuation of running the hotel whether it being through selling knowledge embedded products and services and/or solely knowledge itself through licensing a chain business. The value of hotels' knowledge is revealed when it is applied in various operational activities to generate economic value. Thus, in some hotels the pursuit of a right approach can give them an opportunity to expand in size, in others they are still small.

This paper identifies four different paths to knowledge management in the context of small and mediumsized hotels. In principle all organisations need and can benefit from knowledge management, much of the emphasis in the literature has been on its implementation within large organisations. A significant volume of past research literature tends to exclude specific reference to small and medium-sized enterprises in the hotel context. Thus, this study contributes to a reduction of a gap in the literature of knowledge management, where currently the dominant focus is on large organisations. Although the path options represent practical approaches to knowledge management that can be adopted and further shaped by the hotels, organisational factors that might affect the paths to knowledge management is unclear which needs further study. 


\section{References}

AP\&QC International Benchmarking Clearinghouse. (1996) Knowledge management: Consortium benchmarking study final report, Houston, American Productivity \& Quality Centre.

Argyris, C., and Schön, D. (1996) Organisational Learning 2 :Theory, Method and

Practice, Addison-Wesley.

Barney, J. B. (1991) Firm Resources and Sustained Competitive Advantage, Journal of Management, 17, 99-120.

Bohn, R. (1994) Measuring and Managing Technological Knowledge, Sloan Management Review, Fall, $61-73$.

Boisot, M. H. (1998) Knowledge Assets: Securing Competitive Advantage in the Information Economy, New York, Oxford University Press.

Brown, J., and Duguid, P. (1998) Organizing knowledge, California Management Review, 40(3), 90112.

Bukowitz, W., and Williams, R. (2000) The knowledge management fieldbook, London, Prentice Hall.

Davenport, T. H., and Prusak, L. (1997) Information ecology: Mastering the information and knowledge environment, New York, NY, Oxford University Press.

Davenport, T. H., and Prusak, L. (1998) Working knowledge: How organizations manage what they know, Boston, MA, Harvard business School Press.

Demarest, M. (1997) Understanding Knowledge Management, Long Range Planning, 30(3), 374-384.

Desouza, K. C. and Awazu, Y. (2006) Knowledge Management at SMEs: five peculiarities, Journal of Knowledge Management, 10(1), 32-43.

Earl, M. (2001) Knowledge management strategies: Toward a taxonomy, Journal of Management Information Systems, 18(1), 215-233.

Eccles, R. (1991) The Performance Measurement Manifesto, Harvard Business Review, JanuaryFebruary, 131-137.

Edvinsson, L., and Malone, M. S. (1997) Intellectual Capital: Realizing Your Company's True Value by Finding its Hidden Brainpower, New York, Harper Business.

Everett, R. (1995) Diffusion of Innovations, New York, NY, Free Press.

Grant, R. M. (1991) Prospering in ally competitive environments: organizational capability as knowledge integration, Organization Science, 7, 375-387.

Grant, R. M. (1996) Toward a Knowledge-Based Theory of the Firm, Strategic Management Journal, 17, Winter special issue, 109.

Hansen, M. T., Nohria, N., and Tierney, T. (1999) What's your strategy for managing knowledge?, Harvard Business Review, 77(2), 101-116.

Kaplan, R. S., and Norton, D. P. (1996) The Balanced Scorecard, Boston, MA, Harvard Business School Press.

Mahoney, J., and Pandian, J. R. (1992) The resource-based view within the conversation of strategic management, Strategic Management Journal, 13(5), 363-380.

Matlay, H. (2000) Organisational learning in small learning organisations: an empirical overview, Education and Training, 42(4), 202-211.

McAdam, R., and Reid, R. (2001) SME and large organisation perceptions of knowledge management: comparisons and contrasts, Journal of Knowledge Management, 5(3), 231-241.

Meyer, M., and Zack, H. M. (1996) The design and implementation of information products, Sloan Management Review, 37(3), 43-59.

Nonaka, I. (1994) A dynamic theory of organizational knowledge, Organization Science, 5(1), 14-37.

Nonaka, I., and Takeuchi, H. (1995) The knowledge-creating company: how Japanese companies create the dynamics of innovation, New York, Oxford University Press.

Polanyi, M. (1966) The tacit dimension, London, UK, Routledge \& Kegan Paul.

Porter, M. E. (1980) Competitive Strategy: Techniques for analysing industries and competitors, New York, Free Press.

Porter, M. E. (1985) Competitive Advantage: Creating and Sustaining Superior Performance, New York, Free Press. 
Powell, W. W. (1990) Neither market nor hierarchy: network forms of organisations, Staw, B.

Cummings, L. L., Research in Organisational Behaviour, 12, JAI Press, Greenwich, CT, 295 -336.

Prahalad, C. K., and Hamel, G. (1990) The core competence of the corporation, Harvard Business Review, 68, May-June, 79-91.

Roos, G., and Roos, J. (1997) Measuring your Company's Intellectual Performance, Long range planning, 30(3), 413-427.

Ruggles, R. L. (1998) The state of the notion: knowledge management in practice, California Management Review, 40(3), 80-89.

Rumelt, R. P. (1984) Towards a strategy theory of the firm, In R. Lamb (Ed.), Englewood Cliffs, Prentice-Hall.

Senge, P. M. (1990) The Fifth Discipline: The Art and Practice of The Learning

Organization, New York, NY, Doubleday.

Sparrow, J. (2001) Knowledge management in small firms, Knowledge and Process Management, 8(1), 3-16.

Spender, J. (1996) Making knowledge the basis of a dynamic theory of the firm, Strategic Management Journal, 17, Winter, 45-62.

Stewart, T. A. (1997) Intellectual capital: The new wealth of organisations. New York, Currency Doubleday.

Sveiby, K. E. (1997) The New Organizational Wealth: Managing and Measuring Knowledge-Based Assets, San Francisco, CA, Berrett-Koehler.

Teece, D. J. (1998) Capturing Value from Knowledge Assets: The New Economy, Markets for KnowHow, and Intangible Assets, California Management Review, 40, 55-79.

uit Beijerse, R. P. (2000) Knowledge management in small and medium--sized companies: Knowledge management for entrepreneurs, Journal of Knowledge Management, 4(2), 162-179.

Wenger, E. (1998) Communities of Practice: Learning, Meaning and Identity, Cambridge, Cambridge University Press.

Wernerfelt, B. (1984) A resource-based view of the firm, Strategic Management Journal, 5, 171-180.

Wickert, A. and Herschel, R. (2001) Knowledge-Management Issues for Smaller Businesses, Journal of Knowledge Management, 5(4), 329-337.

Wiig, K. (1993) Knowledge management foundations: Thinking about Thinking-How People and Organisations Create, Represent and Use Knowledge, Arlington, TX, Schema Press.

Wiig, K. M. (2007), Effective Societal Knowledge Management, Journal of Knowledge Management, 11(5), 141-156.

Wong, K. Y. and Aspinwall, E. (2004), Characterizing Knowledge Management in the Small Business Environment, Journal of Knowledge Management, 8(3), 44-61. 